\title{
Sergio Capparelli: a diferença entre distribuir e construir 0 saber $^{1}$
}

\section{Por Luciana Mielniczuk}

Doutora; Universidade Federal do Rio Grande do Sul

luciana.mielniczuk@gmail.com

\section{Luiz Artur Ferraretto}

Doutor; Universidade Federal do Rio Grande do Sul luiz.ferraretto@uol.com.br

Coordenador do PPGCOM (Programa de Pós-graduação em Comunicação e Informação) da UFRGS (Universidade Federal do Rio Grande do Sul), entre 1996 e 2000, no período de sua implantação, o professor e pesquisador Sérgio Capparelli fez uma palestra no dia 20 de agosto de 2015 em evento comemorativo aos 20 anos do Programa que ajudou a criar. Nesta ocasião, concedeu entrevista à revista Intexto. 0 professor contextualiza questões relacionadas ao ambiente de reflexão que antecedem a época da criação do PPGCOM e expõe suas ideias sobre o ofício de ser professor e pesquisador.

Como jornalista, nos anos 1970 e 1980, Capparelli passou pelas redações dos jornais Folha da Manhã e Zero Hora. Foi professor na PUCRS (Pontifícia Universidade Católica do Rio Grande do Sul) e na Unisinos (Universidade do Vale do Rio dos Sinos) antes de iniciar a carreira docente na UFRGS no início dos anos 1980. É escritor, autor de romances e livros infantis, pelos quais recebeu os prêmios "Jabuti", da Câmara Brasileira do Livro, "Odilo Costa Filho", da Fundação Nacional do Livro Infantil e Juvenil, e "Açorianos”, da Prefeitura Municipal de Porto Alegre. No campo da Comunicação, é autor, entre outras contribuições, dos livros Comunicação de massa sem massa (1979), Televisão e capitalismo no Brasil (1982) e Ditaduras e indústrias culturais no Cone Sul da América Latina (1991). Atualmente, aposentado da carreira de professor, dedica-se totalmente à literatura.

1 Colaboraram na realização desta entrevista os técnicos de áudio José Eloi Ferreira Lopes, Dickson Ricardo dos Santos Martins e Neudimar da Rocha (gravação) e os estudantes de Comunicação Social - Jornalismo Paloma da Silveira Fleck e Ricardo Augusto Pereira Santos (degravação). 
Não pensando apenas na Universidade Federal do Rio Grande do Sul, você poderia descrever o ambiente de pesquisa aqui em Porto Alegre nos anos que antecederam a criação dos programas de pós-graduação na área?

De 1976 a 1982, lecionei na PUC; de 1978 a 1980, na Unisinos; e, de 1980 em diante, aqui na Universidade Federal do Rio Grande do Sul. Isso me permite uma visão comparada do que acontecia em termos de pesquisa. Naquele período, estavam separadas as habilitações em Jornalismo, Publicidade e Relações Públicas na UFRGS, na PUCRS e na Unisinos. É também nesse período que acontecem no Rio Grande do Sul reuniões científicas para discutir pesquisa na área. A bem dizer, pesquisar era um acontecimento novo dentro da Comunicação, especialmente na UFRGS. No mais das vezes, eram pesquisas descritivas, poucas chegando a um estágio explicativo ou interpretativo.

Já se sentia necessidade da pesquisa em Comunicação ou esta sensação era mais tênue?

Preocupávamos com entender o papel do jornalismo naquele momento político, em decorrência do golpe de 1964 e a posterior democratização. Nossas atenções voltavam-se acentuadamente para as questões políticas e de mercado da Comunicação. É bom lembrar que a Cooperativa de Jornalistas de Porto Alegre existiu de 1974 a 1983. Ao lado de ideias novas, dinâmicas, discutia-se também um novo jornalismo, modelos antigos em forma e conteúdo versus modelos novos. Tempo da revista Realidade, dos jornais Movimento, Pasquim e Jornal da Tarde, de São Paulo, que inovavam. Por outro lado, não se tratava de uma escolha apenas de jornalismo gráfico como objeto de estudo. As transformações da Rede Globo levantavam perguntas. Em resumo, tínhamos um campo amplo para estudar, mas faltavamnos ferramentas. Daí a tendência descritiva das pesquisas da época. De certa forma, uma contradição. De um lado uma época extremamente politizada - ditadura militar, redemocratização - e a ânsia de se compreendê-la em suas inter-relações com a Comunicação. Acontece que o corpo docente dos cursos de Comunicação também se recompunham. Quem eram os professores? Alguns nem tinham formação universitária. Trabalhavam no Diário de Notícias, trabalhavam na Zero Hora, trabalhavam no Correio do Povo. Predominava nessa clivagem geracional o esforço de apenas ensinar os jovens a escrever para os jornais. Não novas linguagens, novos temas ou novos saberes. Não, nada disso. Repetir um saber sabido e não um saber criado. Mas, como disse, o corpo docente se recompunha. Aquele primeiro grupo de professores, que existiu nos anos 1960 - e mesmo nos anos 1970 -, deixava a universida- 
de por aposentadoria. No entanto, eram endógenas as escolhas dos novos professores. Como eram ainda raros os programas de pós-graduação no país, muitos graduados, apenas formados, passavam no dia seguinte a professores. Sem passarem pelo mercado e também sem experiência acadêmica. Uma época em que todos se faziam perguntas sobre Comunicação e seu contexto, mas sem saber como buscar as respostas.

Em termos de embasamento mais teórico e reflexivo, já existiam naquele momento disciplinas do tipo Fundamentos Científicos de Comunicação ou Teorias da Comunicação?

Já existiam algumas disciplinas como Científicos de Comunicação ou Sociologia da Comunicação, fruto de uma preocupação mais ampla. Uma preocupação que dizia respeito aos objetos de uma universidade, ou seja, um espaço de reflexão e de criação de saberes. Reflexão e saber crítico, bem entendido, para que o estudante de Publicidade, Relações Públicas ou Jornalismo não se reduzisse a um arremedo do mercado. 0 campo da Comunicação, que existia enquanto fazer, enquanto ação, enquanto mercado, expandia-se enquanto campo de estudo e de saber. Um estudo e um saber ainda a ser construído. Mas como construí-lo? E como resolver as questões teóricas e metodológicas, capazes de enquadrar o que então era entusiasmo e boas intenções?

\section{Não se fazia, portanto, a ligação entre o mais teórico e o mais instrumental?}

Essa ligação era difícil porque a requalificação do corpo docente trouxe problemas inesperados. Antes eram profissionais de jornais, como foi dito, despreparados formalmente em termos sociológicos, históricos, políticos etc. Em outras palavras, tinham competência sobre o fazer jornal, publicidade ou relações públicas, mas faltava-lhes uma teoria que lhes servisse de base. Para suprir essa deficiência, reformulações acadêmicas de currículos trouxeram para a Comunicação as perspectivas das Ciências Humanas e Sociais. Um professor do departamento de História dava aulas de História e depois, voltava para o departamento de origem. A interface criada era insuficiente, porque o professor de história em questão carecia de conhecimentos específicos de Comunicação. Em outras palavras, os práticos de Jornalismo, de Publicidade ou de Relações Públicas são substituídos por um corpo docente alheio a um saber específico. Queríamos, naquela época, uma Sociologia, sim, mas Sociologia da Comunicação, voltada para o campo jornalístico. Eram as preocupações da época aqui no sul, com um novo fermento: a partir dos anos 1980, os ex-alunos - agora professores que 
ingressaram na academia sem passar pela pós-graduação - já começam a falar em História da Comunicação, especificamente em História do Jornalismo, Teoria do Jornalismo, Jornalismo e Sociedade e assim por diante. Diferenciam-se dos pioneiros, que tinham os cursos de Jornalismo, Publicidade e Relações Públicas como escolas técnicas ou de treinamento para o mercado de trabalho.

No caso específico da Faculdade de Biblioteconomia e Comunicação, a FABICO, quando se começou a falar em criar um curso de pós-graduação?

Na segunda metade dos anos 1980. Por que tão tarde? 0 corpo docente tinha poucos mestres e carecia de doutores. Na primeira reunião, no início dos anos 1990, concluiu-se que nem a Comunicação nem a Biblioteconomia tinham um número suficiente de docentes para cumprir as exigências da Capes. Daí essa ideia de unir Comunicação e Informação. Nas discussões, ficou claro que o Rio Grande do Sul tinha urgência de um programa de pósgraduação em instituição pública, porque a escola pública fazia parte da história pessoal de cada um. Boa parte tinha estudado em universidade pública. Sem ela, não teriam tido condições de estudar. Meu sentimento - e também de outros membros do grupo - era de retribuir. A satisfação de retribuir, dentro do modelo de universidade pública.

\section{Qual a especificidade daquela proposta inicial para o PPGCOM?}

Qual a identidade do programa? Em que será diferente? Como uma equipe de pequenas proporções poderia levar adiante o projeto? Era o que nos perguntávamos. Nessa época, predominava na América Latina um movimento de integração. Uma tentativa dos países da região de se olharem nos olhos, na busca de uma identidade regional. Boa parte desses países encerrava ciclos ditatoriais e os substituía pela democracia. Integração antes de tudo, dizia-se no Cone Sul. Daí o nosso foco inicial: Comunicação e Indústrias Culturais no Cone Sul.

\section{Como foi a passagem do mestrado para o doutorado?}

Viu-se, depois, que ocorriam discussões na UFRGS, na PUC e na UNISINOS contemporaneamente sobre a criação de mestrado. Logo depois a PUC e a UNISINOS dão início aos seus programas. Explicação? A UFRGS, órgão público, era intrinsecamente mais lento, devido ao seu processo de decisões, principalmente quanto à contratação de professores. Um 
órgão público não contrata professores tendo às mãos um menu à la carte. Os professores só ingressam nos programas através de concursos públicos e é longo o tempo de maturação entre um concurso e outro. Daí o fato de que, apesar de serem contemporâneos, os projetos das três universidade, suas implantações foram diversas no tempo. Havia outra razão subjacente para que o programa de pós-graduação em Comunicação existisse na UFRGS: os três programas da área metropolitana davam o primeiro passo, com a formação de numerosos mestres, que passaram a trabalhar na graduação em todo o estado e em outros lugares no país. Acontece que o mestrado é apenas um primeiro passo. Quanto ao programa de doutorado, a UFRGS tinha condições de ter um centro de excelência em estudos de Comunicação sem as limitações da esfera privada.

O que é, então, ser pesquisador em uma universidade pública? Qual o caminho para os que pretendem se dedicar à pesquisa em uma instituição como a UFRGS?

A base principal que eu vejo está na diferença entre distribuir o saber sabido e construir o saber. Alguém pode ser um professor apenas ensinando o saber sabido, este que existe nos livros. Caminho diferente é criar o saber, que depende de pesquisa. Neste sentido é que as universidades públicas, através das próprias universidades, mas com a supervisão do CNPq e Capes, sistematizaram a pesquisa da graduação ao doutorado. 0 apoio aconteceu com a implementação de bolsas de iniciação científica na graduação, bolsas de mestrado, de doutorado e de pós-doutorado. Dentro desse processo, o estudante participa de pesquisa pouco depois de ingressar na universidade, como bolsista de iniciação científica. Isso foi possível com mudanças na oferta de disciplinas que passaram a incluir teoria e metodologia científica, antes ausentes da grade curricular. E, o que é importante, com professorespesquisadores capazes de orientá-los.

Qual o diferencial em ser um pesquisador da Comunicação em uma instituição pública no Brasil?

Na maior parte dos casos, em uma instituição pública, o pesquisador é uma pessoa privilegiada. Claro, na área de Comunicação, esse privilégio existe também na PUCRS e na UNISINOS, porque são universidades de qualidade. Mas não é o que acontece no resto do Brasil, onde muitas vezes os professores pesquisam nas horas vagas, sem um quadro de carreira definido. Não se pode esquecer também que no início a região foi beneficiada com um grande contingente de pesquisadores formado em programas públicos de pós-graduação, 
como a Universidade de São Paulo e a Universidade do Rio de Janeiro, as primeiras a serem implantadas. Ainda hoje, no Brasil como um todo, os pesquisadores estão concentrados em escolas públicas.

\section{Capparelli, qual é a sua contribuição pessoal para o campo da Comunicação?}

Dia desses eu me fazia essa pergunta. E me veio a imagem de um carro encrencado na estrada. Os passageiros não sabem o que fazer para pô-lo em movimento. Alguém opina que o motorista tome a direção enquanto os outros empurram. 0 motor dá sinal de vida e o entusiasmo é grande. 0 carro avança, não lento demais, para que o motor não morra, não muito rápido, para que a equipe consiga tomar o seu lugar e seguir viagem. Essa imagem explica apenas o início. Um tranco, uma fagulha, e o programa de mestrado se põe em movimento. Para onde? Para o terreno desconhecido do mestrado e para a estrada íngreme e tortuosa do doutorado. No curto prazo, essa foi minha contribuição. Peguei a direção no início, mas logo, e por diversos momentos, fui eu também que empurrei o carro, junto com os outros professores. Esta resposta, no entanto, é parcial. A pergunta vai além do Programa de Pósgraduação em Comunicação e Informação da UFRGS. Ela indaga sobre a contribuição pessoal não só ao Programa, mas à Comunicação como um todo. Poderia dizer que trabalhei intensamente e fiz do ensino e da pesquisa em Comunicação o centro de minha vida. Não quer dizer que tenha sido um excelente professor ou um excelente pesquisador. Longe disso. Digo apenas que trabalhei duramente em tempos difíceis para o Brasil, e em tempos novos para a Comunicação. Posso também dizer que escrevi diversos livros na área, o que dá uma ideia desse meu esforço e desse meu trabalho. Mas tenho dúvidas do alcance do que foi realizado. Por exemplo: que importância tem hoje todo o trabalho feito? Televisão e Capitalismo no Brasil, por exemplo, que ganhou o Prêmio Jabuti de Ciências Humanas em 1982, é um livro histórico, mas datado. Um livro que revela as preocupações da época em que foi escrito. Sua linguagem é tosca, em termos de ciência. Como disse, datada. 0 projeto da pesquisa era um trabalho conjunto com a ABEPEC (Associação Brasileira de Ensino e Pesquisa em Comunicação), a sociedade científica da época, que contou com o protagonismo do professor José Marque de Melo. E Comunicação de massa sem massa? Da mesma forma que o anterior, trata-se de uma publicação que analisou jornal, rádio, situação da pesquisa no Brasil e na América Latina, mas observo hoje pouco fôlego diante das injunções da história. 0 mesmo posso dizer de Ditaduras e indústrias culturais na América Latina ou Enfim sós, a nova televisão no Cone Sul. Considero então letra morta? Não, não é verdade. Os livros, mesmo aqueles escri- 
tos há quase 40 anos, sedimentam muito suor, muito trabalho, muitas noites em claro e um imenso entusiasmo. Pode ser que com a idade não tenhamos mais agilidade de entrar no carro em movimento depois do tranco do motor. Mas o que fazer nessas circunstâncias? Nada. Isso é parte da condição humana.

\section{Referências}

CAPPARELLI, S. Comunicação de massa sem massa. São Paulo: Summus, 1979.

CAPPARELLI, S. Televisão e capitalismo no Brasil. Porto Alegre: L\&PM, 1982.

CAPPARELLI, S. Ditaduras e indústrias culturais no Cone Sul da América Latina. Porto Alegre: UFRGS, 1991.

Recebido em 12/11/2015

Aceito em 16/12/2015 